\title{
Effect of Instruction with Visual Materials Based on Health Belief Model on Global Warming Perception Among University Students
}

\author{
Samia Ali El-Nagar, Entsar Abd El Aleem Abd Elsalam, Naglaa Abd El-Mawgoud Ahmed \\ Community Health Nursing, Faculty of Nursing, Menoufia University, Shibin Elkom, Egypt
}

Email address:

entsargodia@gmail.com (E. A. El A. A. Elsalam)

To cite this article:

Samia Ali El-Nagar, Entsar Abd El Aleem Abd Elsalam, Naglaa Abd El-Mawgoud Ahmed. Effect of Instruction with Visual Materials Based on Health Belief Model on Global Warming Perception among University Students. American Journal of Nursing Science.

Vol. 6, No. 3, 2017, pp. 209-217. doi: 10.11648/j.ajns.20170603.19

Received: March 11, 2017; Accepted: March 21, 2017; Published: April 11, 2017

\begin{abstract}
Global warming is one of the most critical environmental problems of 21 thcentury. It is not only environmental hazard but also social and economic risk and unfortunately some adverse consequences of it are becoming visible these days. Therefore, it is a great importance for educating people and making them aware of this problem. The study was aimed to examine the effect of instruction with visual materials based on health belief model on global warming perception among university students. Quasi experimental design with pre and post-test was utilized. This study was conducted at six faculties from both scientific and literary faculties in Shebin Elkom City at Menoufia University. Systematic random sample consisted of 360 university students including 144 males and 216 females aged between 18 to 22 years old who enrolled in the first academic years of both selected scientific and literary faculties in Shebin Elkom City. The following tools were used 1. Self-administered structured questionnaire which involved socio-demographic data and knowledge of university students about global warming. 2. Perception of students about global warming based on health belief model. The main result of this study showed that there was significant improvement in the knowledge and perception of university students' about global warming after instruction with visual materials compared to before instruction. Additionally, there was statistically significant relation between students' knowledge and perception toward global warming. The current study concluded that, instruction with visual materials was effective in improving knowledge and perception of university students about global warming. This result recommended that, the need for developing and establishing of environmental protection education programs to enhance environmental awareness of all students from elementary school to university level.
\end{abstract}

Keywords: Global Warming, Instruction, Visual Materials, Perception, University Students, Health Belief Model

\section{Introduction}

Global warming is one of the greatest important problems facing the world. It is defined by Environmental protection agency, as the current and ongoing rise in the temperature of the earth due to the increased greenhouse effect occurring as a result of greenhouse gases mainly carbon dioxide, nitrous oxide, methane, chlorofluorocarbons and ozone that produced from human activities, such as burning of coal, oil, and natural gas, deforestation and various agricultural and industrial practices [1-4]. The United Nations International Panel on Climate Change in 2014 reported that more than ninety five percent of scientists are assured that global warming is mostly produced by human activities, chiefly increase concentrations of greenhouse gases [5].

The health influences from climate change have been recognized, for example increased cardiopulmonary, communicable, allergic, mental illnesses and a host of weather-related injuries [6]. In 2009 the World Bank described Egypt as particularly vulnerable to global warming effects. Egypt is the fifteenth most populated country in the world and particularly liable to adverse environmental consequences of human-induced climate change. Expected consequences consist of rise in sea level, water deficiency, agriculture, food insufficiency, and pressures on health of human and national economy. The influences of rising sea 
level on coastal areas, agricultural sector will be the most $(90 \%$ loss $)$, followed by the industrial $(65 \%$ loss $)$ and tourism sectors ( $55 \%$ loss) due to sea level rise of $0.5 \mathrm{~m}$. Fisheries and tourism are thus two further economic activities likely to be harmfully impacted by climate change [7].

Egyptian Environmental Affairs Agency (EEAA) has established and approved the strategy of disseminating environmental awareness all over the country among schoolchildren and teenagers. In addition, several training programs have been achieved by the EEAA for adolescence and concentrating on the link between health and environment [8].

The adverse impacts of global warming can be disastrous and a potential threat to the humanity existence [9]. Therefore, it is essential for everyone, to understand how change of climate influence them and what can they do for coping, understanding what is the global warming reasons and effects to find out resolutions and implement them [10]. It is a great importance for teaching people and making them aware of this problem through including global warming topics in educational curricula at every level, and by illuminating the misunderstanding of students and people about global warming received from the mass media. Currently, environmental instruction of global warming from basic school to the college level is the best effective way to raise the environmental awareness among nations [11-13]

The health belief model (HBM) had been developed to clarify the probability of health-related behavior from an individual viewpoint. It has been frequently used to recognize preventive health behaviors besides modification behavior to reduce environmental pollution that has human health impacts [14]. The elements of the HBM are perception of vulnerability, severity, benefits, and barriers to action, as well as cues to action and self-efficacy. Perceived vulnerability and barriers had been revealed to be linked with preventive behavior but perceived severity, benefits, and barriers had been the greatest related to treatment of a condition [15].

Health belief model can be capable to predict modification and adaptation behavior if global warming is perceived as a health threat. The time-frame for modification is long-range while adaptation is more immediate but both actions are important and complementary, and are not commonly exclusive [16]. Public health agencies should reach the community with behavior modification messages through social marketing or communication campaigns using the health framework [15].

Nurses are in an excellent position to provide guidance in implementing the principles of reduce, reuse, recycle, recover and re-educate in the workplace [17]. Also, nurses can begin to educate people around the changes that they can make in their houses and will have a vast influence on the environment. Turn-off electrical devices not in use, hanging the laundry outside to dry, driving a fuel efficient car, use energy effective light bulbs, walking to work, planting a tree, bringing own bags to the grocery store, recycling, and by supporting environmentally friendly companies that will help to decrease waste, reduce toxic releases and greenhouse gases in atmosphere [18].

Visual aids help in keeping discipline in the class since all the students' attention is focused in learning. Also this interactive session develops critical thinking and cognitive that is important components of the teaching-learning process. Visual materials offer opportunities for effective communication between teacher and students in learning. Traditional verbal instructions can be painful for students. However, use of visual materials provides intrinsic motivation to students by peaking their curiosity and stimulating their interests in the subjects, Constructing learning in sense skill, spreading experience, encouraging participation, motivating interest, individualizes instructions, aids as a source of information, making leaning permanent [19]. Taber \& Taylor (2009) revealed that individual activities and effective visual education tools significantly improved students' information levels about global warming and climate change [13].

\subsection{Significance of the Study}

A healthy environment is fundamental to life; therefore attention to the effects of the environment on human health is vital to achieve the goal of health for all. As nurses working in the health care career we have a responsibility to the people of the world to be an environmental health activist and raise awareness about effects of environmental changes on health, to support policies, decrease health vulnerability and build capacity to adapt towards climate change [20].

Global warming is the most environmental hazard of our time. It threatens our health, communities, economy, and national security. Although local temperatures swing naturally, the usual global temperature over the previous 50 years has increased at the fastest rate in recorded history [21]. In Egypt, the future estimates of usual temperature increases are likely to reach $+4{ }^{\circ} \mathrm{C}$ in Cairo and from +3.1 to $4.7^{\circ} \mathrm{C}$ in the rest of Egypt by 2060 and falls in annual rainfall may account to 10 to $40 \%$ over most of Egypt by 2100 [7]. Several international agreements were signed to reduce the greenhouse gases effects concentration in the atmosphere on international levels, but reduction on a national level is also significant to accomplish this international goal and awareness is one of the main steps to achieve that [22]. Therefore, the aim of this work was to study the effect of instruction with visual materials based on HBM on global warming perception among university students.

\subsection{Aim of the Study}

The aim of this study was to examine the effect of instruction with visual materials based on health belief model (HBM) on global warming perception among university students. This aim achieved through:

1. Assessing the student's knowledge and perception regarding global warming.

2. Designing, implementing and evaluating the effect of instruction with visual materials based on health belief model on global warming perception among university 
students.

\subsection{Hypotheses}

1. Knowledge of university students' about global warming will be improved after receiving instruction with visual materials compared to before instruction.

2. Perception of university students' about global warming based on HBM will be improved after instruction with visual materials compared to before instruction.

3. There will be a significant relation between students' knowledge and perception about global warming.

\section{Subjects and Methods}

\subsection{Research Design}

Quasi experimental design with pre and post-test was utilized to accomplish the aim of this study.

\subsection{Research Setting}

This study was conducted at six faculties in Shebin Elkom City, Menoufia University, including three scientific faculties (Home economy, Nursing and Science) and three literary faculties (Commerce, Law and Arts).

\subsection{Sample}

Systematic random sample consisted of 360 university students including 144 males and 216 females aged between 18 to 22 years old who enrolled in the first academic years of both selected scientific and literary faculties in Shebin Elkom City, Menoufia University. A multistage random sampling technique was used to select sample:

1. First stage included random selection of 6 faculties including three scientific and three literary faculties out of 11 faculties in Shebin Elkom City, Menoufia University.

2. Second stage included random selection of one academic year from each faculty.

3. Third stage included random selection of students from the first academic years of each selected faculty through using a systematic random sample technique.

Sample Size

The number of undergraduate students was selected according to the following equation:

Sample size $n=\left[D_{E F F} * N p(1-p)\right] /[(d 2 / Z 21-\alpha / 2 *(N-1)+$ $\left.p^{*}(1-p)\right]$

1. Total university students in the first academic year (population size ) of about 5000 in the selected faculties in Shebin ElKom, Menoufia university during year 2014 i: e $(\mathrm{N})=5000$

2. Hypothesized $\%$ frequency of the problem in the population (p): $30 \%+/-5$

3. Confidence limits as $\%$ of 100 (absolute $+/-\%$ )(d): $5 \%$

4. Design effect (for cluster surveys-DEFF):

5. Sample Size (n) for $95 \%$ Confidence Levels was 357 which were approximate to 360 students.

\subsection{Tools of the Study}

\subsubsection{Self-Administered Structured Questionnaire}

It was developed by the researchers after reviewing the related literature and included the following:

A. Socio-demographic data: It was included student's age, gender, type of faculty, academic year, and residence.

B. Knowledge of university students about global warming: It was included 9 items such as meaning of global warming, meaning of greenhouse, the greatest gas which impact on global warming, activities contribute to global warming, effect of global warming on environment, effect of global warming on health, the most polluting fuel to vehicles, source of renewable energy, and individuals preventive activities that aim at environment protection and reduction of harmful gas emissions and global warming. Response of items in the form of alternative options with only one correct answer. Each correct answer was given one score based on predetermined key answer according to the literature, while incorrect and don't know answer was given zero. Then the knowledge scores were summed to obtain a total knowledge score $(9$ score).

Scoring System for Students' Knowledge About Global Warming Was Categorized as Follow

1. Poor knowledge $(<50 \%)$.

2. Fair knowledge $(50-75 \%)$.

3. Good knowledge $(>75 \%)$.

\subsubsection{Perception of Students About Global Warming (Based on HBM)}

Perceptions of students about global warming were measured using the HBM as the theoretical framework. The HBM has been generally used to understand preventive health behaviors and modification behavior to reduce environmental pollution effects on human health. The main components of the HBM used in this study were perceived vulnerability, perceived severity, perceived benefit of taking preventive measures, perceived barriers to the preventive action and cues to taking action. This included a number of items for each component of the HBM. Perceived vulnerability for harmful effects of global warming on lifestyle and health (7 items), perceived severity and health risk from global warming (4 items), perceived benefit of taking preventive measures or activities aimed at environment protection and reduction of harmful gas emissions ( 9 items), perceived barriers to taking the preventive action or environmentally friendly behaviors ((7 items), and cues to taking action is the presence of information and other stimulates that motivates to take preventive action ( 1 item). The researchers were asked students to provide responses on a two-point Likert scale (disagree, agree) scored from 1 to 2 respectively. Then each component score was calculated and divided into low/high perception.

Scoring System for Students' Perception About Global Warming Using HBM Was Categorized as Follow

1. Low perception $(<75 \%)$.

2. High perception $(\geq 75 \%)$. 


\subsection{Validity and Reliability of Tools}

Tools were developed by the researchers after reviewing the related literature and tested for its content validity. Validity indicated the degree to which the tool measures what it is expected to measure. It was determined by a panel of experts in community medicine and community health nursing and modifications were carried out according to the panel judgment on clarity of the sentences and appropriateness of the contents. A reliability analysis was carried out in order to examine the internal consistency of its questions and identify the extent to which the items of tools measured the same concept and correlate with each other. The reliability was measured by Cronbach's Alpha coefficient test. The value of Cronbach's alpha for knowledge about global warming was 0.85 and perception about global warming based on HBM was 0.80 . The value of Cronbach's alpha for each component of HBM such as perceived vulnerability was 0.78 perceived severity was 0.87 perceived benefit was 0.83 perceived barriers was 0.76 and cues to taking action was 0.85 . This indicating that the instrument was consistent and reliable in achieving the study.

\subsection{Pilot Study}

Pilot study was conducted on 30 undergraduate students from both scientific and literary faculties. The pilot sample was not included in the total sample of the research work. The pilot study was carried out to test the applicability and clarity of the constructed questionnaire and detect any problems that might arise during the actual collection of data. According to the results of the pilot study, the necessary modifications and clarifications of some questions were done. Then the final form was developed and used in data collection.

\subsection{Ethical Considerations}

Researchers followed all the ethical issues in conducting the research. Informed consent was obtained from the participants who were willing to participate in the study. The participants were informed that participation in this study is voluntary; they can withdraw at any time during the study without giving reasons. The researchers were explained the aim of the study to all university students in the study sample. They reassured that any obtained information would be strictly confidential.

\subsection{Data Collection Procedure}

1. This study was conducted during the period starting from February 2014 to the end of May 2014.

2. Necessary approval was obtained from the dean of each selected faculty after issuing letters to them from the Faculty of Nursing, Menoufia University explaining the aim of the study in order to obtain permission and help. Also, meetings were done with the heads of departments' which were selected in each faculty to explain the aim of the research and method of data collection to obtain permission for conducting the study.

3. After obtaining approval and informed consent to conduct the study, the researchers were initiated data collection from university students who fulfilled the selection criteria two days per week for four months through using self-administered structured questionnaire which included socio demographic data, knowledge of students about global warming and perception of students about global warming based on health belief model.

4. Before distributing the questionnaire, the researchers introduced themselves and a brief explanation about the purpose of the study was given to the students. Questionnaires were distributed to the selected participants who agree to participate in the study. The researchers were present during data collection for any clarifications to the subjects about questionnaires.

5. The average time taken for completing questionnaires was around 20-25 minutes.

6. The obtained data used as the baseline assessment (pre -test). The researchers were developed instructions with visual materials aimed to improve student's knowledge and perception regarding global warming.

7. Visual instructional materials used in this study included videos, documentary film, power point presentations, pictures and posters.

8. Students taken from each faculty were divided into groups; each group consists of 15-20 students. They were given instructions with visual materials about global warming in lecture room in two sessions and the duration of each session was 50-60 minutes.

9. First session included videos, documentary film giving information about greenhouse effect, the reasons or activities which contribute to global warming and consequences of global warming on environment and health.

10. Second session included power point presentation, pictures and posters about preventive activities aimed at environment protection and the environmentally friendly behaviors needed to control global warming individually in and outside the home.

11. In the last session, students were given a guide booklet about global warming reduction. This booklet was developed by the researchers after reviewing the related literature.

12. At the end of intervention period (two months) post -test was performed by using the same pretest questionnaire.

\subsection{Statistical Analysis}

Data was entered and analyzed by using SPSS (Statistical Package for Social Science) statistical package version 16. Graphics were done using Excel program. Quantitative data were presented by mean (X) and standard deviation (SD). It was analyzed using student t- test for comparison between two means, and ANOVA (F) test for comparison between more than two means. Qualitative data were presented in the form of frequency distribution tables, number and percentage. It was analyzed by chi-square $(\chi 2)$ test. However, if an expected value of any cell in the table was less than 5, Fisher Exact test was used( if the table was 4 cells), or Likelihood test (if the table was more than 4 cells). Level of significance was set as $P$ value $<0.05$ for all significant tests. 


\section{Results}

Table 1. Distribution of demographic data of university students $(n=360)$.

\begin{tabular}{lll}
\hline Demographic characteristics & No. & \% \\
\hline Age (years): Mean \pm SD & $19.8 \pm .77$ & 40 \\
Sex: & & 60 \\
Males & 144 & 65 \\
Females & 216 & 35 \\
Type of faculty: & 234 & 66.1 \\
literary & 126 & 33.9 \\
Scientific & & 238 \\
Residence: & 122 & \\
Rural & & \\
Urban
\end{tabular}

Table 1. Shows that, the mean age of university students was $19.8 \pm 77$ years. More than half $(60 \%)$ of students were females, about two thirds $(65 \%)$ were from literary faculties and $66.1 \%$ of students from rural areas.

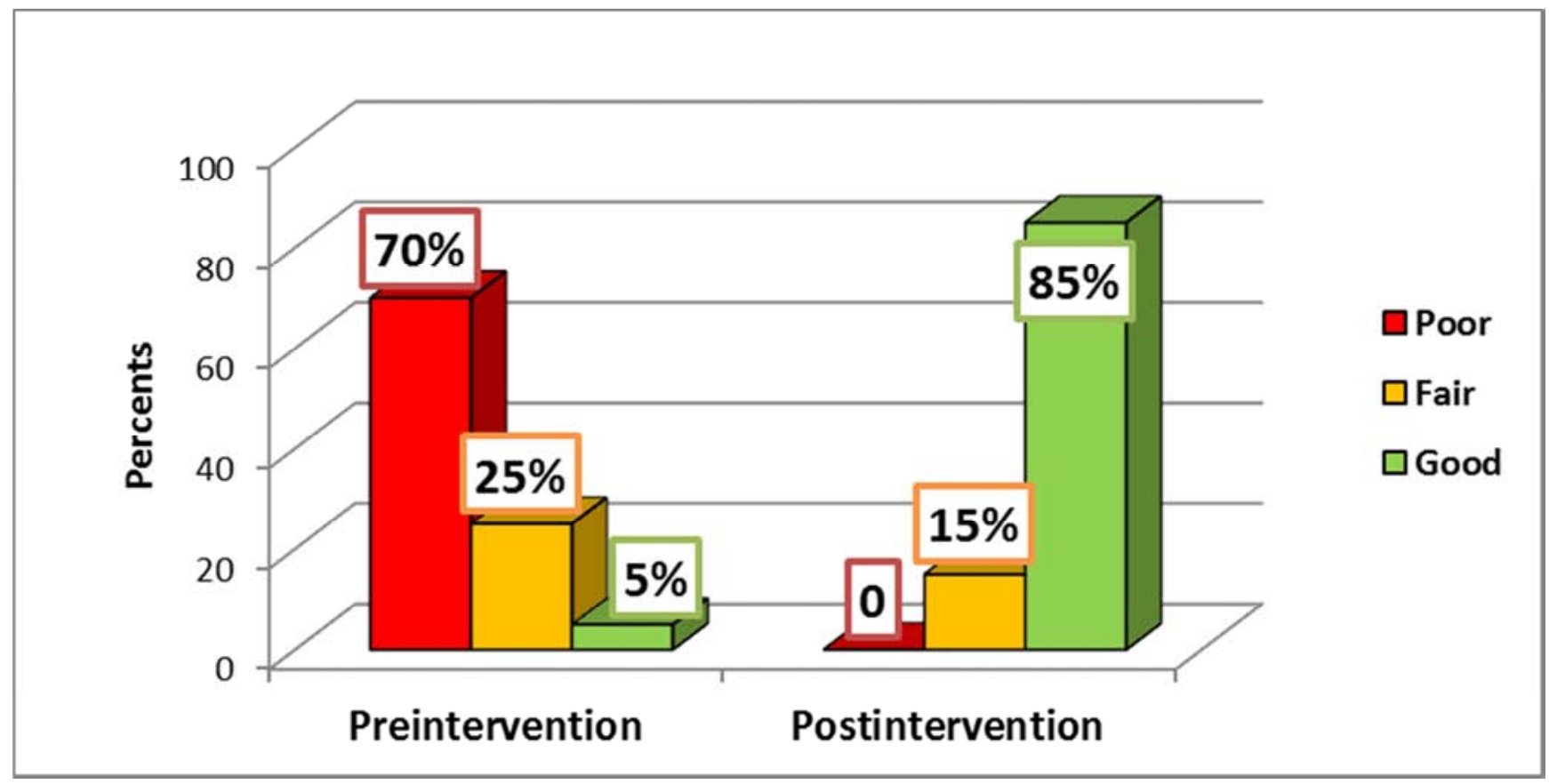

Figure 1. Knowledge levels of university students before and after intervention.

Figure 1: Reveals that before instruction with visual materials the majority ( $70 \%$ ) of students had poor knowledge about global warming while only $5 \%$ had good knowledge compared to after instruction, most of students had good knowledge ( $85 \%$ ) with statistically significant differences between pre and post intervention ( $\mathrm{LR}=42.5, \mathrm{P}=0.000)$.

Table 2. Mean score of knowledge and perception of university students about global warming based on health belief model before and after instruction (360).

\begin{tabular}{|c|c|c|c|}
\hline \multirow{3}{*}{ Mean score of knowledge and perception } & \multicolumn{2}{|l|}{ Groups } & \multirow{3}{*}{ Paired t- test } \\
\hline & Pre-intervention & Post-intervention & \\
\hline & Mean $+S D$ & $M e a n+S D$ & \\
\hline Knowledge about global warming & $2.75 \pm 1.1$ & $8.0 \pm 1.2$ & $\mathrm{t}=20.6 \mathrm{p}<0.000$ \\
\hline Perceived vulnerability to global warming problem & $9.4 \pm 1.2$ & $13.3 \pm 0.9$ & $\mathrm{t}=32.8 \mathrm{p}<0.000$ \\
\hline Perceived severity of global warming & $9.3 \pm 1.2$ & $13.3 \pm 0.9$ & $\mathrm{t}=32.8 \mathrm{p}<0.000$ \\
\hline Perceived benefits of taking preventive activities & $12.2 \pm 2.5$ & $16.3 \pm 1.3$ & $\mathrm{t}=26.7 \mathrm{p}<0.000$ \\
\hline Perceived barriers of take action to reduce risk of global warming & $8.9 \pm 1.3$ & $12.8 \pm 1.2$ & $\mathrm{t}=30.7 \mathrm{p}<0.000$ \\
\hline
\end{tabular}

Table 2: Reveals that there was significant improvement in the mean score of students' knowledge about global warming after instruction $(8.0 \pm 1.2)$ compared to pre instruction $(2.75 \pm$ 1.1). Additionally, this table shows that there was significant improvement in the mean score of university students perception including perceived vulnerability, perceived severity of global warming, perceived benefits of taking preventive activities and perceived barriers of take action to reduce risk of global warming after instruction with visual materials compared to before instruction. 


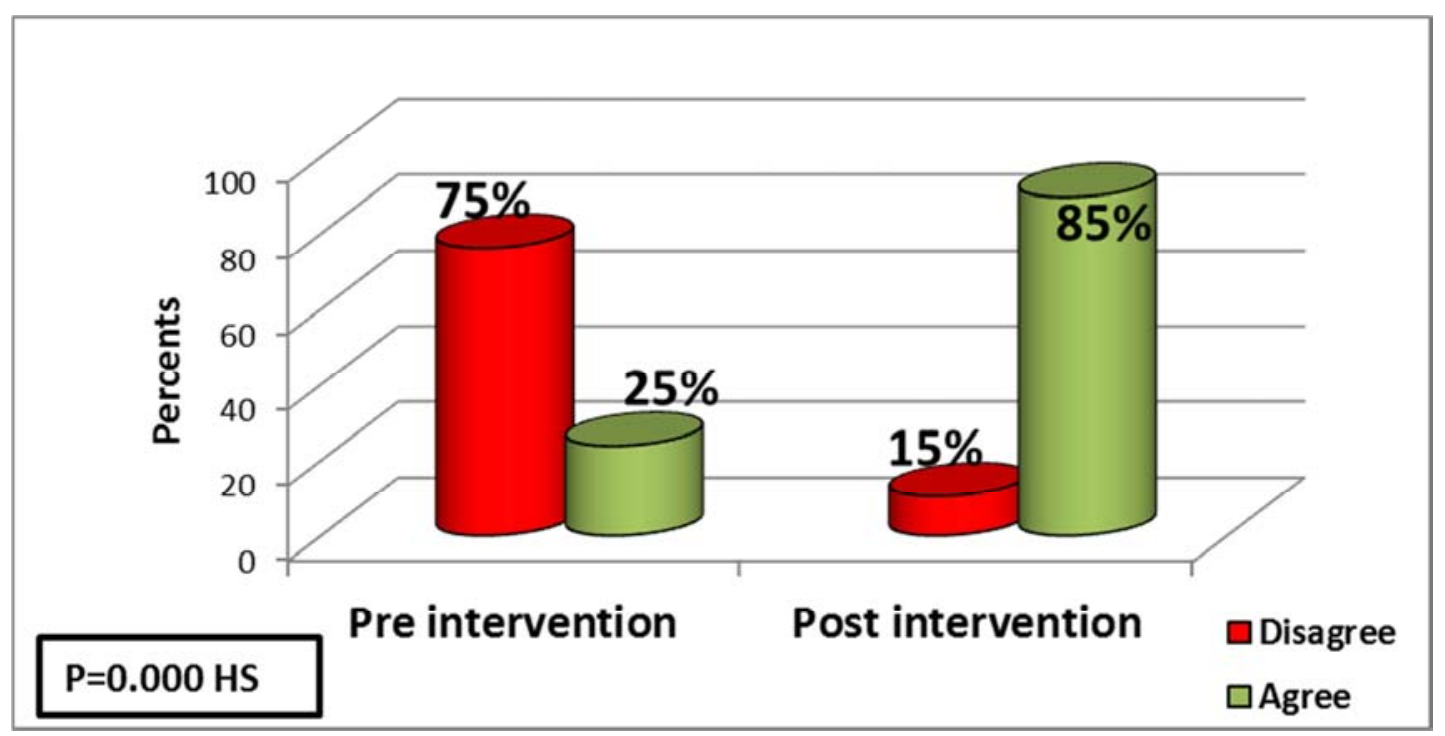

Figure 2. Cues of action before and after instruction among university students.

Figure 2: Illustrates, that after instruction, the majority $(85 \%)$ of students agreed that they had the necessary information to face global warming impacts as well as the confidence and ability to protect themselves from health impacts of climate change compared to pre instruction (25\%) with statistically significant difference between pre and post instruction.

Table 3. Distribution of students' perception about global warming based on health belief model before and after instructions $(n=360)$.

\begin{tabular}{|c|c|c|c|c|c|}
\hline \multirow{3}{*}{ Items of student' perception } & \multicolumn{4}{|c|}{ Groups } & \multirow{3}{*}{ P value } \\
\hline & \multicolumn{2}{|l|}{ Pre } & \multicolumn{2}{|l|}{ Post } & \\
\hline & No. & $\%$ & No. & $\%$ & \\
\hline \multicolumn{6}{|c|}{ Perceived vulnerability to global warming problem } \\
\hline Low perceived vulnerability & 180 & $50 \%$ & 54 & $15 \%$ & \multirow[t]{2}{*}{$\mathrm{X} 2=100.4, \mathrm{P}=0.000 \mathrm{HS}$} \\
\hline High perceived vulnerability & 180 & $50 \%$ & 306 & $85 \%$ & \\
\hline \multicolumn{6}{|c|}{ Perceived severity of global warming } \\
\hline Low perceived severity & 180 & $50 \%$ & 126 & $35 \%$ & $\mathrm{X} 2=16.5, \mathrm{P}=0.000 \mathrm{HS}$ \\
\hline \multicolumn{6}{|c|}{ Perceived benefits of taking preventive activities } \\
\hline Low perceived benefits & 162 & $45 \%$ & 108 & $30 \%$ & \multirow[t]{2}{*}{$\mathrm{X} 2=17.2, \mathrm{P}=0.000 \mathrm{HS}$} \\
\hline High perceived benefits & 198 & $55 \%$ & 252 & $70 \%$ & \\
\hline \multicolumn{6}{|c|}{ Perceived barriers of take action to reduce risk of global warming } \\
\hline Low perceived barriers & 198 & $55 \%$ & 126 & $35 \%$ & \multirow[t]{3}{*}{$\mathrm{X} 2=29.1, \mathrm{P}=0.000 \mathrm{HS}$} \\
\hline High perceived barriers & 162 & $45 \%$ & 234 & $65 \%$ & \\
\hline Total & 360 & $100.0 \%$ & 360 & $100.0 \%$ & \\
\hline
\end{tabular}

Table 3: This table shows that there was significant improvement in perception level of students about global warming including perceived vulnerability, perceived severity of global warming, perceived benefits of taking preventive activities and perceived barriers of take action to reduce risk of global warming after instruction with visual materials compared to before instruction.

Table 4. Distribution of knowledge level and perception of university students about global warming by literary and scientific faculties ( $n=360$ ).

\begin{tabular}{|c|c|c|c|c|c|c|c|c|c|c|}
\hline \multirow{3}{*}{ Levels of items: } & \multicolumn{5}{|c|}{ Pre intervention } & \multicolumn{5}{|c|}{ Post intervention } \\
\hline & \multicolumn{2}{|c|}{ literary } & \multicolumn{2}{|c|}{ Scientific } & \multirow{2}{*}{$\begin{array}{ll}\text { P1 } \\
\text { value }\end{array}$} & \multicolumn{2}{|c|}{ literary } & \multicolumn{2}{|c|}{ Scientific } & \multirow{2}{*}{$\begin{array}{l}\text { P2 } \\
\text { value }\end{array}$} \\
\hline & No. & $\%$ & No. & $\%$ & & No. & $\%$ & No. & $\%$ & \\
\hline \multicolumn{11}{|l|}{ Knowledge level: } \\
\hline Poor & 144 & $61.5 \%$ & 108 & $85.7 \%$ & \multirow{3}{*}{$0.000 * *$} & 0 & 0 & 0 & 0 & \multirow{3}{*}{0.78} \\
\hline Fair & 90 & $38.5 \%$ & 1 & 0 & & 36 & $15.4 \%$ & 18 & $14.3 \%$ & \\
\hline $\begin{array}{l}\text { Good } \\
\text { Perceived vulnerability: }\end{array}$ & 0 & 0 & 18 & $14.3 \%$ & & 198 & $84.6 \%$ & 108 & $85.7 \%$ & \\
\hline Low & 108 & $46.2 \%$ & 72 & $57.1 \%$ & \multirow[t]{2}{*}{$0.04 *$} & 30 & $12.8 \%$ & 24 & $19 \%$ & \multirow[t]{2}{*}{0.72} \\
\hline High & 126 & $53.8 \%$ & 54 & $42.9 \%$ & & 204 & $87.2 \%$ & 102 & $81 \%$ & \\
\hline $\begin{array}{l}\text { Perceived severity: } \\
\text { Low }\end{array}$ & 216 & $92.3 \%$ & 108 & $85.7 \%$ & $0.04 *$ & 108 & $46.2 \%$ & 18 & $14.3 \%$ & $0.000 * *$ \\
\hline
\end{tabular}




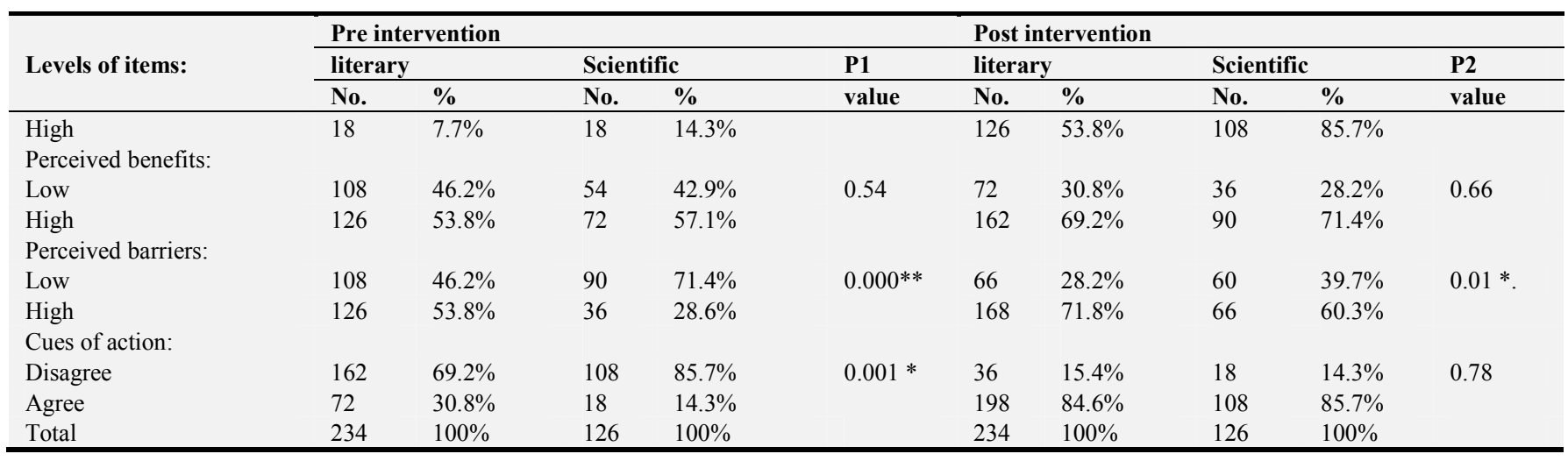

$\mathrm{P} 1$ = Comparison between literary and Scientific Faculties in different items pre intervention P2 = Comparison between literary and Scientific Faculties in different items post intervention $* *=$ high significance $*=$ significance

Table 4: Illustrates that, $61.5 \%$ of literary faculties students and $85.7 \%$ of scientific faculties students had poor knowledge about global warming with statistically significant difference between both groups at pre intervention compared to post intervention, the significant improvement where $84.6 \%$ of literary faculties students and $85.7 \%$ of scientific faculties students had good knowledge about global warming with no statistically significant difference between both groups. In addition there was statistical significant difference between literary and scientific students in relation to items of perception and cues of action about global warming pre intervention compared to post intervention; the statistical significant difference was regard to perceived severity and perceived barriers only.

Table 5. Relation between knowledge levels and perception of university students about global warming at pre and post intervention.

\begin{tabular}{|c|c|c|c|c|c|c|c|c|c|c|c|c|}
\hline \multirow{3}{*}{ Levels of perception } & \multicolumn{7}{|c|}{ Pre intervention knowledge levels } & \multicolumn{5}{|c|}{ Post intervention knowledge levels } \\
\hline & \multicolumn{2}{|c|}{ Poor } & \multicolumn{2}{|l|}{ Fair } & \multicolumn{2}{|c|}{ Good } & \multirow{2}{*}{$\begin{array}{l}\text { P1 } \\
\text { value }\end{array}$} & \multicolumn{2}{|c|}{ Fair } & \multicolumn{2}{|c|}{ Good } & \multirow{2}{*}{$\begin{array}{l}\text { P2 } \\
\text { value }\end{array}$} \\
\hline & No. & $\%$ & No. & $\%$ & No. & $\%$ & & No. & $\%$ & No. & $\%$ & \\
\hline \multicolumn{13}{|l|}{ Perceived vulnerability: } \\
\hline Low & 180 & $71.4 \%$ & 0 & $0 \%$ & 1 & $0 \%$ & $0.000 * *$ & 14 & $25.9 \%$ & 40 & $13.1 \%$ & $0.00 *$ \\
\hline High & 72 & $28.6 \%$ & 90 & $100 \%$ & 18 & $100 \%$ & & 40 & $74.1 \%$ & 266 & $86.9 \%$ & \\
\hline \multicolumn{13}{|l|}{ Perceived severity: } \\
\hline Low & 234 & $92.9 \%$ & 72 & $80 \%$ & 18 & $100 \%$ & $0.001 *$ & 36 & $66.7 \%$ & 90 & $29.4 \%$ & $0.000 * *$ \\
\hline High & 18 & $7.1 \%$ & 18 & $20 \%$ & 0 & 0 & & 18 & $33.3 \%$ & 216 & $70.6 \%$ & \\
\hline \multicolumn{13}{|l|}{ Perceived benefits: } \\
\hline Low & 162 & $64.3 \%$ & 0 & $0 \%$ & 0 & $0 \%$ & $0.000 * *$ & 14 & $25.9 \%$ & 94 & $30.7 \%$ & $0.000 * *$ \\
\hline High & 90 & $35.7 \%$ & 90 & $100 \%$ & 18 & $100 \%$ & & 40 & $74.1 \%$ & 201 & $69.3 \%$ & \\
\hline \multicolumn{13}{|l|}{ Perceived barriers: } \\
\hline Low & 180 & $71.4 \%$ & 0 & $0 \%$ & 18 & $100 \%$ & $0.000 * *$ & 16 & $29.6 \%$ & 85 & $27.8 \%$ & $0.000 * *$ \\
\hline High & 72 & $28.6 \%$ & 90 & $100 \%$ & 0 & $0 \%$ & & 38 & $70.4 \%$ & 221 & $72.2 \%$ & \\
\hline Total & 252 & $100 \%$ & 90 & $100 \%$ & 18 & $100 \%$ & & 54 & $100 \%$ & 306 & $100 \%$ & \\
\hline
\end{tabular}

$\mathrm{P} 1$ = Comparison between levels of students' knowledge in different items pre intervention

$\mathrm{P} 2$ = Comparison between levels of students' knowledge in different items post intervention

$* *=$ High significance $*=$ Significance

Table 5: Shows that, the students who had poor or fair knowledge about global warming they had low perception, while the students who had good knowledge they had high perception level about global warming in both pre and post intervention.

\section{Discussion}

A major scientific and political issue in the current century is global warming [11]. The impacts of global warming are being felt across the globe. Extreme heat waves have caused tens of thousands of deaths around the world in recent years. Scientists agree that environmental, economic, and health consequences are likely to occur if current trends continue [23].

Concerning knowledge level of university students the current study revealed that there was significant improvement in knowledge level and means score after application of instructions with visual materials. This result was in agreement with Chakraborty et al., (2015) [24] who studied an intervention study on knowledge of global warming among school students of kolkata, West Bengal, India. They found that following intervention, significant improvement was observed in mean score of students' knowledge of intervention group. In addition Gutierrez, (2016) [25] who investigated the climate changes beliefs, knowledge, behaviors, and cultural worldviews of rural middle school students and their families during an out-of-school intervention. He stated that, significant gains in climate change content knowledge can be attained through short-term out-of-school interventions.

Regarding students' perceptions the present study showed that there was significant improvement in the mean score of 
university students perception based on HBM, including perceived vulnerability, perceived severity of global warming, perceived benefits of taking preventive activities and perceived barriers of take action to reduce risk of global warming after instruction with visual materials compared to before instruction. This result was in the same line with Cao et al., (2014) [26] who examined health belief model based evaluation of school health education programme for injury prevention among high school students in the community context. They revealed that the health belief model score was significantly higher after intervention. Also, a study conducted by Reza et al., (2016) [27] to examine" efficacy of HBM-based dietary education intervention on knowledge, attitude, and behavior in medical students" this study showed that following the educational intervention, the mean score of health belief model structure, and behavior of students in relation to healthy patterns of food intake increased significantly.

In regard to cues of action, the present study illustrated that after instruction, the majority of students agreed that they had the necessary information to face global warming impacts as well as the confidence and ability to protect themselves from health impacts of climate change. This result was in the same line with Akompab et al., (2013) [28] who studied heat waves and climate change: applying the health belief model to identify predictors of risk perception and adaptive behaviors in Adelaide, Australia. They revealed that, participants with a high perceived benefit, a high cues to action, who had additional training or education after high school were more likely to have good adaptive behaviors during a heat wave. In addition, Cao et al., (2014) [26] who reported that perceived susceptibility and cues to action were the second and third most important components of HBM respectively, and the score of them improved after intervention.

Regarding difference between literary and scientific faculties' students in relation to knowledge, the present study showed that there was no statistical significant difference between literary and scientific students in relation to knowledge after instructions compared to pre instructions the scientific students were more knowledgeable than literary, which can be attributed to involvement of environmental related topics in their curriculum. This result was in accordance with Freije et al., (2015) [29] who studied that global warming awareness among the university of Bahrain science students. They observed tangible differences in awareness among the students across different departments, where the biology and physics students were more knowledgeable than the mathematical students. University students' awareness of environment, global warming, and greenhouse effect, specifically science students, is expected to be one of the highest among students in the formal educational pyramid, and an important indicator to the knowledge of the general population. The United Arab Emirates University (UAEU) had reported that students from the college of science and Food and Agriculture were more aware of environmental impact in comparison to students from other colleges [30].

Concerning the relation between students' knowledge and perceptions the current study reported that students who had high score of perceptions were more knowledgeable than others, that may be due to the more knowledge and information about certain crisis can lead to increase the perception about it. This result was in contrast with Cardwell, (2011) [31] who studied knowledge, attitudes and practices of global environmental change and health: toward sustainable behavior change. He reported that, although participants are environmentally aware and concerned about local environmental issues, detailed knowledge of specific causes, impacts and risks of climate change and global warming is limited.

Concerning applying of health belief model the current study verified that health belief model was successful in improving students' knowledge and perception. This result was in agreement with a study conducted by Akompab et al., (2013) [28] they specified that the health belief model could be valuable to guide the strategy and implementation of interventions to stimulate adaptive behaviors during heat waves. Also this result was consistence with Reza et al., (2016) [27] who revealed that the significant improvement in the study group's mean knowledge, HBM component, and behavior scores point to the positive effect of the intervention.

\section{Conclusion}

Based on the results of this study, it was concluded that, there was significant improvement in the knowledge of university students' about global warming after instruction with visual materials compared to before instruction. There was significant improvement in the perception of university students' about global warming based on HBM after instruction with visual materials compared to before instruction. Additionally, there was statistically significant relation between students' knowledge and perception toward global warming.

\section{Recommendations}

Based on the results of this study, the following recommendations were suggested:

1. The need for developing and establishing of environmental protection education programs to enhance environmental awareness of all students.

2. Encourage students to adopt environmentally friendly behaviors to minimize dangers of global warming.

3. The ministry of health in collaboration with the ministry of education must hold training program from elementary school to university students' to enhance their environmental awareness.

\section{References}

[1] Gul, A., Topay, M., Ozaydin, O., (2009). Against the threat of global warming, the importance of urban forest. In: Paper Presented at the International Davraz Congress, Isparta, Türkiye.

[2] Ozbayrak, O., Uyulgan, M., Alpat, S., Alpat, S. K., Kartal, M., (2011). A research on high school students knowledge related to global warming. Buca Eg itim Faku" ltesi Dergisi 29, 58 67. 
[3] Environmental Protection Agency (EPA). (2013a). Frequently asked questions about global warming and climate change: back to basics. Available at:

http://www.epa.gov/climatechange/basics/.

[4] Environmental Protection Agency (EPA). (2013b). Overview of greenhouse gases Available at:

http://www.epa.gov/climatechange/ghgemissions/gases.html.

[5] Intergovernmental Panel on Climate Change (IPCC). (2013): Climate Change: The Physical Science Basis - Summary for Policymakers, Observed Changes in the Climate System, p. 15, in IPCC AR5 WG1 2013.

[6] Friel, S., Bowen K., Campbell-Lendrum, D. (2011): Climate change, non-communicable disease, and development: the relationships and common policy opportunities. Ann Rev of Public Health, 32: 133-147.

[7] Mohamed, M. (2009): Environment in Jeopardy: Consequences of climate change in Egypt. Journal of Ecology and the Natural Environment Vol. 1(5), pp191-195.

[8] Ministry of State for Environmental Affairs (2009). Egyptian Environmental Affairs Agency. Achievements and planned activities: environmental education, training and awareness. Available from:

http://www.eeaa.gov.eg/english/main/accompl3.asp.

[9] Aydin, F., (2010). Secondary school students' perceptions towards global warming: a phenomenographic analysis. Sci. Res. Essays 5 (12), 1566-1570.

[10] United Nations Environment Program (UNEP). (2013). The emission gas report 2013: A UNEP synthesis. Available at: http://www.unep.org/pdf/UNEPEmissionsGapReport2013.

[11] Skamp, K. R., Boyes, E., Stanisstreet, M., (2009). Global warming responses at the primary secondary interface: 2 potential effectiveness of education. Aust. J. Environ. Educ. $25,31-44$.

[12] Taber, F., Taylor, N., (2009). Climate of concern: A search for effective strategies for teaching children about global warming. Int. J. Environ. Sci. Educ. 4 (2), 97-116.

[13] Kilinc, A., Boyes, E., Stanisstreet, M., (2011). Turkish school students and global warming: beliefs and willingness to act. Eurasia J. Math. Sci. Technol. Educ. 7 (2), 121-134.

[14] Brody, S. D., Vedlitz, A., Grove, R. H. (2008). Examining the relationship between physical vulnerability and public perceptions of global climate change in the United States. Environment and Behavior, 40, 72-95.

[15] Semenza, J. C., Ploubidis, G. B., \& George, L. A. (2011). Climate change and climate variability: personal motivation for adaptation and mitigation. Environmental Health, 10: 46.

[16] Biesbroek GRSR, Knaap GM van der (2008): The mitigation-adaptation dichotomy and the role of spatial planning. Habitat International 33: 230-237.

[17] Canadian Nurses Association (2006). The Ecosystem, the Natural Environment, and Health and Nursing: A Summary of the Issues. CNA Backgrounder. Available at: www.can-aiic.ca.

[18] Hunt, G. (2007). Global Warming and the Future of Healthcare and Nursing. Royal College of Nurses Annual Congress.
[19] Ashaver, D., Igyuve, S., (2013): The use of audio-visual materials in the teaching and learning processes in Colleges of Education in Benue State-Nigeria. IOSR Journal of Research \& Method in Education (IOSR-JRME) Volume 1, Issue 6 PP 44-55.

[20] World Health Organization. (2005) Climate and Health: Fact Sheet. Geneva.

[21] Natural Resources Defense Council (NRDC). (2011). An introduction to Climate Change retrieved on 9-2015. Available at: http://www.nrdc.org/climate/default.asp.

[22] Arslan, S., (2012). The Influence of environment education on critical thinking and environmental attitude. Proc. Social Behav. Sci. 55, 902-909.

[23] MacMillan A, (2016): Global Warming101. Available at https://www.nrdc.org/stories/global-warming-101 Retrived, February 27, 2017.

[24] Chakraborty D, Mondal T., Mojumdar D., Naskar N. N. (2015): An intervention Study on Knowledge of Global Warming among School Students of Kolkata, West Bengal, India. IOSR Journal of Dental and Medical Sciences (IOSR-JDMS) e-ISSN: 2279-0853, p-ISSN: 2279-0861. Volume 14, Issue 12 Ver. IX (Dec. 2015), PP 01-04.

[25] Gutierrez K. (2016): Investigating the Climate Change Beliefs, Knowledge, Behaviors, and Cultural Worldviews of Rural Middle School Students and their Families During An Out-of-School Intervention: A Mixed-Methods Study. A dissertation submitted to the Graduate Faculty of North Carolina State University in partial fulfillment of the requirements for the Degree of Doctor of Philosophy.

[26] Cao Z., Chen Y. \& Wang S. (2014): Health belief model based evaluation of school health education programme for injury prevention among high school students in the community context. BMC Public Health. DOI: 10.1186/1471-2458-14-26.

[27] Reza T., Hossein D., Fateme R., Gholami F. (2016): Efficacy of HBM-Based Dietary Education Intervention on Knowledge, Attitude, and Behavior in Medical Students. Iranian Red Crescent Medical Journal. Vol. 18 Issue 11, p1-7. 7p.

[28] Akompab D. Bi P., Williams S., Grant J., Walker I \& Augoustinos M. (2013): Heat Waves and Climate Change: Applying the Health Belief Model to Identify Predictors of Risk Perception and Adaptive Behaviors $\backslash$ in Adelaide, Australia. Int J Environ Res Public Health. 2013 Jun; 10 (6): 2164-2184.

[29] Freije A, Hussain T, Salman E, (2015): Global warming awareness among the University of Bahrain science students. Journal of the Association of Arab Universities for Basic and Applied Sciences. The article in press.

[30] AbuQamar, S., Alshannag, Q., Sartawi, A., Iratni, R. (2015): Educational awareness of biotechnology issues among undergraduate students at the United Arab Emirates University. Biochem. Mol. Biol. Educ. 43 (4), 283-293.

[31] Cardwell F, (2011): Knowledge, Attitudes And Practices Of Global Environmental Change And Health: Toward Sustainable Behaviour Change? A thesis submitted to the school of graduate studies in partial fulfillment of the requirements for the degree master of arts. McMaster University. 